Europe's Journal of Psychology 1/2010, pp. 14-43

www.ejop.org

\title{
Anger as a moderator of the relationships between attachment, dyadic adjustment, and childhood victimization in physically violent spouses
}

\author{
Claude Bélanger \\ University of Quebec in Montreal \\ McGill University and Douglas Hospital Research Center \\ Hélène Brisebois \\ University of Quebec in Montreal
}

\begin{abstract}
The present study examines the moderating effects of the anger characteristics of violent husbands on the relationships between a set of predictors and both psychological and physical husband violence. Based on data from 76 married violent men recruited through community organizations that work with abusive males, a series of moderated multiple regression analyses showed that anger repression and felt intensity of anger does moderate the effects of attachment, dyadic adjustment, and childhood victimization on physical violence, but not on psychological violence. Considering that anger repression and felt intensity of anger are the more internally-related anger characteristics experienced in the couple relationship leads to the suggestion that the more covert characteristics of anger are more likely to play a moderating role than the overt characteristics, and reinforce the idea that it would be advantageous to consider anger as a multidimensional construct in studies of violence.
\end{abstract}

Keywords: support seeking, care giving, conflict management, observational data

Introduction

Marital violence and specifically husband violence are increasingly a focus of attention in North America. More than 500,000 American women are injured yearly as a result of partner violence and require medical treatment (Tjaden and Thoennes, 2000). The National Violence Against Women (NVAW) Survey was conducted from 1995 to 1996 and sampled both American women and men. Analysis of survey data on the prevalence, incidence, and consequences of violence sheds light on many 
aspects of the problem. First, specifically referring to physical partner violence, it revealed that women are more likely to be victims of violence than men: $22.1 \%$ of women, compared with $7.4 \%$ of men, reported they had been physically assaulted by a current or former spouse, cohabiting partner, boyfriend or date in their lifetime. Also, nearly two-thirds of women who reported having been raped, physically assaulted, or stalked since the age of 18 had been victimized by intimate partners. Moreover, among women who were physically assaulted or raped by a partner, a third of the cases resulted in injury. A more recent survey in Canada revealed that among women, $30 \%$ have experienced at least one act of physical or sexual violence from their partner (Statistics Canada, 2001). Husband violence still appears to be underreported but women are more likely to report violent incidents to the police when the abuse occurs after a separation; 44\% of women assaulted by a previous partner seek police assistance (Statistics Canada, 2001). As for intimate abuse in current relationships, occurrence of victimization was brought to the attention of the police in $26 \%$ of cases involving women (Statistics Canada, 2001).

The consequences of partner violence are extensive. It is associated with both shortand long-term problems, including physical injury and illness, psychological symptoms, economic costs, and in the most severe cases, death (National Research Council, 1996). Also, because of severe partner violence, female victims are more likely than male victims to need medical attention and to take time off from work; they also spend more days bedridden because of injuries, and suffer more stress and depression for the same reasons (National Research Council, 1996; Ramos, Carlson, and McNutt, 2004). One important indirect consequence of partner abuse is that each year thousands of American children witness their mother being abused. Childhood witnesses of violence are at risk for long-term physical and mental health problems, including alcohol and substance abuse, victimization, and perpetration of partner violence (Felitti et al., 1998; Albus, Weist, and Perez-Smith, 2004). These pervasive negative consequences of domestic violence are also reported in Canada. A national survey established that women that are victims of marital violence could suffer from various physical traumas, some of them being very serious and even lethal (Statistics Canada, 2002). Moreover it was reported by our team in a recent paper on attachment and marital violence that consequences of marital violence could also be more pervasive and associated with psychological dysfunctions: fear, anxiety and phobias, depression, insomnia and nightmares, etc. (Gosselin, Lafontaine \& Bélanger, 2006).

Until 20 years ago, researchers had paid relatively little attention to the issue of marital violence. A lot of work has been done since then, resulting in a better understanding of the different variables that predict the propensity for a male to 
resort to abusing his partner. However, piecing these results together to paint a more complex picture of male marital violence remains a challenge. There is a need for more integrative studies that would consider the complex relationships that may exist among the constellation of factors that have been linked to partner abuse. The present study investigates the links between husbands' anger and a number of other predictors of husband violence.

Various definitions of husband violence have been used in the scientific literature. This has contributed to some inconsistencies and difficulties in comparing results across studies. Some researchers have focused only on direct physical assaults (Holtzworth-Munroe and Stuart, 1994; Margolin, John, and Gleberman, 1988), whereas others have also included threats of assault and non-physical acts of aggression (Dibble and Straus, 1980; Sharpe and Taylor, 1999). To address the definition issue, a team of researchers designed a test, the Revised Conflict Tactics Scale, that differentiates between psychological aggression, physical assault, and sexual coercion (Straus, Hamby, Boney-McCoy, and Sugarman, 1996), the first two being more widespread in violent husband populations (Tjaden and Thoennes, 2000). Some studies indicate that psychological aggression may often be a precursor to physical violence (Murphy and O'Leary, 1989; O'Leary, Malone, and Tyree, 1994). Accordingly, some authors recommend the inclusion of both types of abuse in studies of marital violence (Barling, 1996).

A wide range of variables have been associated with husband violence, but the complex relationships that exist between the various predictors of this violence had not been studied until relatively recently (Holtzworth-Munroe, 1997). Because of the quantity of correlates of marital violence that have been identified, it may be instructive at this point to determine which of those variables interact to increase or decrease the level of violent behavior by husbands.

Among studies that incorporate several predictors, most focus on clusters of variables that are similar in nature. For instance, Stith and Farley (1993) include cognitive and sociodemographic variables, while Dutton and Starzomski (1994) focus on different aspects of personality organization. It would be useful to have a better understanding of how the various clusters of correlates compare as predictors of husband violence. Predictors of violence could be categorized along many clusters. One of these categorizations could include four types of variables: personal history, personality, dyadic, and psychological variables. For personal history variables, the link to husband violence is more consistent for witnessing interparental violence than it is for parental child abuse (Sugarman and Hotaling, 1989). Few studies have sought to identify moderation effects on those variables, which would 
be of clinical relevance; personal history cannot be acted upon directly, whereas moderators may be amenable to change and thus potentially offer a way of buffering the effects of personal history.

With respect to personality variables, some studies suggest that men who are physically aggressive towards their partner exhibit aspects of borderline personality organization (Dutton, Saunders, Starzomski, and Bartholomew, 1994). It would appear that violence arises in these men as a result of intense anger built up because of frustrated attachment needs (Holtzworth-Munroe et al., 1997) Also, other studies that cast attachment style as a stable personality characteristic (HoltzworthMunroe; Dutton and Starzomski, 1993) indicate that abusive men are dependent on their wives and show preoccupied attachment patterns (Holtzworth-Munroe, 1997). The fact that problematic attachment is itself an underlying component of borderline personality may make it a key aspect in the study of husband violence.

Results for dyadic variables show that violent husbands have less spouse-specific assertiveness skills (Rosenbaum and O'Leary, 1981). In their marital communication patterns, violent couples, as compared to conflictual but non-violent partners, tend to display more negative behaviors (e.g. anger behavior, contempt, and belligerence) that promote a more rigid and highly contingent negative style of communication that is resistant to change (Burman, Margolin, and John, 1993). Violent husbands tend to instigate negative discussions, inculcate fear in their partner, and react aggressively to many violent and non-violent behaviors by their wives (Jacobson et al, 1994). Furthermore, violent couples are more likely to engage in husband demand/wife withdraw communication patterns which correlate significantly with increases in psychological and physical aggression (Babcock, Waltz, Jacobson, and Gottman, 1993; Berns, Jacobson, and Gottman, 1999; Feldman and Ridley, 2000). Marital satisfaction research also reveals that the link with marital violence may not be direct; the presence of other factors, such as husband hostility or husband alcohol use, combined with marital dissatisfaction, contribute to increasing general husband aggression, particularly husband psychological aggression, which then leads to a heightened potential for husband physical aggression (O'Leary, Malone, and Tyree, 1994).

With regard to psychological variables, violent men generally score higher on depression (Julian and McKenry, 1993) and lower on self-esteem (Hotaling and Sugarman, 1986). It is also well accepted among researchers that alcohol abuse is correlated with marital violence and that this relationship may weaken as the abusers grow older (Heyman, O'Leary and Jouriles, 1995). Studies have consistently revealed that violent husbands obtain higher scores for anger and hostility (Dutton 
and Starzomski, 1994; Heyman et al.). Since anger is also known to interact with other psychological variables in predicting problem behaviour (Colder and Stice, 1998), it is suspected to have interaction effects that explain husband violence.

Although in many studies anger has been evoked as an important factor in explaining the escalation of conflicts of violent couples, anger, hostility and aggressivity have often been cited with little distinction between them. Consequently, it is sometimes difficult to know whether the results are indicative of links with hostility or anger (Laughrea, Bélanger, Wright, and McDuff, 1997; Spielberger, 1988). According to Laughrea and her colleagues (1997), anger can be conceived as an emotional state, triggered by a frustrating event or the anticipation of such an event, where feelings vary in intensity from a state of irritability to rage. The notion of hostility also involves feelings of anger but includes a complex set of feelings and attitudes that may motivate aggression and vindictive behavior (Laughrea et al, 1997). The term aggression is primarily used to describe destructive and punitive behavior (Laughrea et al, 1997; Spielberger, Krasner, and Solomon, 1988), and it encompasses psychological and physical violence. Following that line of thought, anger is necessary but not sufficient for hostile and aggressive behaviors to surface (Spielberger, 1988; Spielberger et al, 1988). This observation suggests that anger may play a moderating role in the occurrence of violent acts; its presence may enable a third variable to covary with violence; its absence may inhibit such a relationship. For example, a man who experiences anger following feeling of spouserelated frustration may become violent if he is not satisfied with his marriage, whereas his degree of marital dissatisfaction may not have a bearing on the expression of violence if he is not angry. It would therefore be interesting to investigate whether anger has an indirect relationship to violence. In particular, it would be instructive to see how anger and the expression of anger can modulate the links between various predictors and marital violence. Many studies of marital violence have used hostility and aggression measures without including anger measures (Barnett, Fagan, and Booker, 1991; McKenry et al, 1995; Leonard and Blane, 1992). Anger measures arguably get closer to the inner process that may lead to violence than hostility and aggression measures, which get closer to the overt behaviors of violence that are usually assessed. Our team proposed a typology of anger in an attempt to identify these patterns of couples' anger management profiles (Laughrea, Wright, McDuff \& Bélanger, 2000). Cluster analysis was conducted using five indices of anger derived from Inventory of Anger Experience in Couples (Laughrea, Bélanger, \& Wright, 1996). Sample consisted of 220 couples from normal and clinical populations. Four types of couples were identified: (a) Relaxed Couples, (b) Slightly Angry Couples, (c) Explosive Angry Couples, and (d) Dangerously Enraged Couples. Results also indicated that the higher the disturbance of anger 
dynamics between partners, the more psychologically and maritally distressed they were, and the lower the quality of their coping strategies. Among those types of studies that evaluate the concept of anger in relation to couple violence, many components of anger (e.g. state anger, trait anger, anger-out, anger-in, anger control, range of anger elicitation situations, frequency of anger, duration of anger, magnitude of anger, etc.) have also been identified as correlates of domestic violence ((Laughrea et al., 1996; Dutton et al, 1994; Dye and Eckhardt, 2001; Date and Ronan, 2000).

Although anger has been explored in numerous investigations of marital violence, few anger measures have been developed (Multidimensional Anger Inventory (MAl; Siegel, 1986); State-Trait Anger Expression Inventory (STAXI; Spielberger, 1988)). Instruments that evaluate couple-related anger are even rarer (Inventory of the Experience of Anger in the Couple (IECC; Laughrea et al, 1997); Anger Management Scale (AMS; Stith and Hamby, 2002)). As variables that are congruent (i.e. share elements of context) appear to be more likely to show interaction relationships (Schat and Kelloway, 2003; Tetrick and LaRocco, 1987), anger measures that are specifically designed for the marital experience would be interesting to consider as moderators in that context.

A number of variables have been identified as moderators in studies of husband violence. Margolin (1998) found that alcohol impairment, while not in itself a significant predictor, moderated the effects of life stress and marital dissatisfaction on husband violence. Mauricio and Gormley (2001) found that adult attachment style significantly moderated the relationship between need for dominance and frequency of violence. Lafontaine and Lussier (in press) found that trait anger and anger control played a moderation role in the relationship between low anxious attachment and physical violence in men, but not in women, and they called for more complex models of prediction. By testing models that incorporate more predictors, it may be possible to determine at once whether anger variables play a key moderation role in several relationships between predictors and husband violence. This information could help to design clinical strategies by pointing to factors that have several indirect repercussions on the occurrence of violent acts by husbands.

Lastly, we should note that most of the research that deals with the relationship between anger and closely related concepts (e.g. hostility) and husband violence does not differentiate between psychological and physical violence. Comparatively few studies have dealt specifically with psychological violence, and it appears that this type of aggression is considerably more difficult to predict from direct correlates 
than physical aggression (Black, Schumacher, Smith Slep, and Heyman, 1999). This suggests that interaction relationships between factors may better explain psychological violence. Also, very few studies have compared the respective relationships of anger to psychological and physical husband violence. Such a comparison would provide insight into the differences and similarities between those two forms of violence, e.g. by helping to better understand the complex process of escalation from psychological to physical violence (Murphy and O'Leary, 1989; O'Leary et al., 1994; Laughrea, Wright, McDuff, and Bélanger, 2000).

The main goal of the present study was to examine whether anger in the marital context acts as a moderator for various types of predictors (dyadic adjustment, attachment, childhood victimization, and childhood witnessing interparental violence) of male psychological and physical violence.

We hypothesized that anger would moderate the relationships between the various predictors and both husband physical and psychological aggression. Because psychological violence appears to be more difficult to predict from direct correlates than physical violence (Black et al., 1999), we further hypothesized that husband psychological aggression scores would show stronger interaction effects than physical aggression scores. Lastly, we hypothesized that the strongest interaction of anger as experienced in the couple relationship would be with dyadic adjustment variables, as a corollary of the congruence hypothesis mentioned above (Schat and Kelloway, 2003; Tetrick and LaRocco, 1987).

Method

Participants

Our sample was composed of men recruited through a Canadian community organization that works with violent men in the Montreal area. Of all males who sought help with the organization during the time of our study, 223 French-speaking men agreed to meet with the research team to learn more about the research project and be briefed on confidentiality issues; 76 clients (34\%) actually came to the interview, during which they were asked to give their written consent to participate in the project and to fill out the various questionnaires

Participants' ages ranged from 18 to 58 years old and the average age was 36 years old. Education levels ranged from 2 to 18 years, with an average of 11 years (to high school level). Rounded annual income in Canadian dollars ranged from $\$ 5,000$ to 
more than $\$ 90,000$, and the average income was approximately $\$ 25,000$. Two-thirds of respondents $(N=48)$ were still living with their partner at the time they completed the questionnaires. The men had between 0 and 4 children, with an average of 1.74 children. Among those men, $67 \%$ reported to follow the therapy for violent men for personal reasons, while $33 \%$ of them would report that they would follow the intervention program because they were ordered by the court to do so.

\section{Measures}

Adult Romantic Attachment: A 36-item scale that can be divided into two 18-item subscales measuring two attachment dimensions: anxious attachment style and avoidant attachment style. The original questionnaire by Brennan, Clark, and Shaver (1998) was translated and validated in French by Lafontaine and Lussier (2001). Items were rated on a 7-point scale ranging from 1 (strongly disagree) to 7 (strongly agree). Alpha coefficients are satisfactory in the translated version (.86 for the anxiety scale and .87 for the avoidance scale), and are comparable to the original English version (.91 and .94 respectively).

Dyadic Adjustment Scale: An abbreviated and validated 16-item French version (Lussier, Valois, Sabourin, and Dupont, 1998) that measures the same four subscales as the original English version by Spanier (1976): dyadic satisfaction, dyadic cohesion, dyadic consensus, and emotional expression. The total score combining all subscales is used as the measurement of dyadic adjustment. Five items dealing with agreement between partners in different areas were rated on a 6-point scale ranging from 1 (strongly agree) to 6 (strongly disagree). Four items about attitude and behavior regarding their romantic relationship were rated on a 6-point scale ranging from 1 (always) to 6 (never). One item on common interests outside the home was rated on a 5-point scale ranging from 1 (in all) to 5 (in nothing). Items about the frequency of positive couple interaction were rated on a 6-point scale ranging from 1 (always) to 6 (never). There was one yes/no question on disagreement about manifestation of one's love. The last item, addressing the degree of happiness in the romantic relationship, was rated on a 7-point scale ranging from 1 (extremely unhappy) to 7 (perfectly happy). Alpha coefficients for the short version of the scale are very similar to those obtained with the original version: dyadic satisfaction $(\alpha=.94)$, dyadic cohesion $(\alpha=.86)$, dyadic consensus $(\alpha=.90)$, and affective expression ( $\alpha=.73$ ) (Lussier et al., 1998).

Witnessing Marital Violence. This was assessed with one very brief yes/no question of our own formulation: "When you were a child, did you ever witness acts of marital violence?" 
Victim of Violence. Similarly, this was assessed with one very brief yes/no question of our own formulation: "Were you ever a victim of violence during your childhood?"

Inventory of the Experience of Anger within the Couple. A 32-item validated French version of the STAXI (Spielberger, 1988), adapted to take into account the various components of expression and experience of anger in the context of couple relationships (Laughrea, Bélanger, and Wright, 1996). Numerous aspects of anger toward a romantic partner are evaluated in this questionnaire. In what follows, alpha coefficients indicating internal consistency reliability are listed in parentheses for each subscale. The first part of the questionnaire measures the presence and intensity of anger feelings toward the partner at a specific time (first subscale: anger feelings, $\alpha=.88$ ). The second part of the questionnaire measures the presence of anger personality traits. Two types of anger personality traits are considered: the tendency to become angry regardless of the situation (second subscale: angry temper, $\alpha=.85$ ) and the disposition to express anger when criticized by others (third subscale: angry reactions, $\alpha=.75)$. The sum of the subscales for anger personality traits yields a general anger personality trait subscale (fourth subscale: anger personality trait, $\alpha=.82$ ). The third part of the questionnaire measures the style of expression of anger, with three different subscales: anger repression (fifth subscale, $\alpha=.79$ ), inadequate expression of anger (sixth subscale, $\alpha=.74$ ), and positive anger control (seventh subscale, $\alpha=.87$ ). The sum of the subscales for anger expression style yields a general anger expression score (eighth subscale, $\alpha=.72$ ). The items were rated on a 4-point scale ranging from 1 (almost never) to 4 (almost always).

Psychological and physical violence. Two subscales of a French version of the Revised Conflict Tactics Scale (CTS-2) originally designed by Straus and colleagues (1996) and translated and validated by Lafontaine and Lussier (in press) were used as outcome measures to evaluate psychologically and physically abusive behavior. All items were rated according to the frequency of certain behaviors over the past year in eight different categories, ranging from "none" to "21 or more times". Range midpoints of $0,0,1,2,4,8,15$ and 25 were used for the encoding of scores. For the French version, the alpha coefficient is .71 for the psychological violence scale and it is .78 for the physical violence scale. Alpha coefficients for the English version scales are respectively .79 and .86 .

Psychological violence. An 8-item subscale of the CTS-2 that measures verbal and non-verbal destructive male behaviors. These behaviors could be aimed directly at the partner, or at different objects, with the objective to intimidate and/or ventilate anger. 
Physical violence. A 12-item subscale of the CTS-2 that measures threatening male behaviors or actions. These behaviors are aimed at the female partner's body.

Results

Moderated hierarchical multiple regression analyses were performed to test for the moderation effect of the husbands' couple-related anger subscale scores on the relationship between their attachment, dyadic adjustment, childhood victimization, childhood witnessing of interparental violence, and physical and psychological violence. The first step consisted of normalizing the predictor (i.e. attachment, dyadic adjustment, etc.) and moderator (anger) variables. Our analysis was then conducted using the normalized values.

To investigate the moderating effects of anger subscale scores, the main and interaction effects were entered hierarchically. We entered each individual moderator variable and the predictor into the regression, and the terms that interacted with that moderator were entered into a second block. If the second block accounted for significant incremental variance, a significant moderating effect could be inferred for that particular moderator. This is equivalent to an omnibus test of the moderating effects of each anger characteristic, after controlling for the main effects of the predictor and the moderator variables.

Where moderating effects were found, the significance of each individual interaction term was assessed post hoc through hierarchical moderated regressions. This enabled us to determine which interactions of the predictor and anger variables would predict violence.

Because our predictions of the moderating effects of anger characteristics depend on interaction effects, and because interaction effects supersede direct effects (Pedhazur, 1973), we interpreted the results using interaction effects.

Before conducting the analyses, we examined the data for violations of assumptions and outliers. We did not find any serious outliers, but the distributions of psychological and physical violence variables were positively skewed. A square root transformation restored normality to the distribution of psychological violence, and a fourth root transformation did likewise for the physical violence variable. Descriptive statistics, internal consistency coefficients, and intercorrelations for all of the study variables are provided in Table 1. 
Table 1: Descriptive statistics, internal consistency coefficients, and intercorrelations of study variables

\begin{tabular}{|c|c|c|c|c|c|c|c|c|c|c|c|c|c|c|c|c|c|}
\hline & Mean & SD & 1 & 2 & 3 & 4 & 5 & 6 & 7 & 8 & 9 & 10 & 11 & 12 & 13 & 14 & 15 \\
\hline 1. Physical Aggression & .934 & 1.64 & $(0.81)$ & $0.51^{* *}$ & -0.16 & -0.05 & $-0.28^{*}$ & -0.21 & $0.40^{* *}$ & -0.18 & 0.01 & 0.17 & 0.17 & $0.23^{*}$ & 0.13 & $0.46^{* *}$ & $-0.25^{*}$ \\
\hline 2. Psychological Aggression & 5.60 & 4.03 & & $(0.72)$ & $-0.24^{*}$ & -0.13 & $-0.54^{* *}$ & $-0.41^{* *}$ & $0.38^{* *}$ & 0.04 & 0.09 & 0.08 & $0.31^{* *}$ & $0.57^{* *}$ & $0.40 * *$ & $0.65^{* *}$ & $-0.43^{* *}$ \\
\hline 3. Dyadic Adj. Consensus & 12.6 & 3.16 & & & $(0.66)$ & $0.43^{* *}$ & $0.51^{* *}$ & $0.41^{* *}$ & $-0.40^{* *}$ & -0.07 & -0.07 & -0.10 & $-0.32^{* *}$ & $-0.26^{*}$ & -0.13 & $-0.25^{*}$ & $0.28 *$ \\
\hline 4. Dyadic Adj. Affective Expr. & 7.15 & 2.42 & & & & $(0.56)$ & $0.38^{* *}$ & $0.35^{* *}$ & $-0.42^{* *}$ & -0.14 & -0.08 & 0.16 & $-0.35^{* *}$ & -0.22 & -0.20 & $-0.24^{*}$ & $0.33^{* *}$ \\
\hline 5. Dyadic Adj. Satisfaction & 15.1 & 4.96 & & & & & $(0.79)$ & $0.79^{* *}$ & $-0.70^{* *}$ & -0.16 & 0.00 & -0.10 & $-0.43^{* *}$ & $-0.46^{* *}$ & $-0.60 * *$ & $-0.57^{* *}$ & $0.28^{*}$ \\
\hline 6. Dyadic Adj. Cohesion & 11.8 & 4.13 & & & & & & $(0.79)$ & $-0.74^{* *}$ & -0.07 & 0.15 & -0.07 & -0.21 & $-0.38 * *$ & $-0.53^{* *}$ & $-0.50^{* *}$ & 0.22 \\
\hline 7. Avoidant Attachment & 2.99 & 1.13 & & & & & & & $(0.88)$ & 0.06 & -0.22 & -0.08 & 0.25 & $0.43^{* *}$ & $0.54^{* *}$ & $0.56^{* *}$ & -0.21 \\
\hline 8. Anxious Attachment & 4.10 & 1.18 & & & & & & & & (0.89) & $0.27^{*}$ & 0.20 & $0.28 *$ & $0.40 * *$ & $0.33^{* *}$ & 0.15 & -0.06 \\
\hline 9. Childhood Witnessa & .510 & .500 & & & & & & & & & N/A & $0.40^{* *}$ & 0.20 & 0.09 & 0.00 & 0.11 & $-0.26^{*}$ \\
\hline 10. Childhood Victima & .588 & .495 & & & & & & & & & & N/A & 0.06 & 0.12 & 0.03 & 0.20 & -0.05 \\
\hline 11. Anger - Felt Intensity & 1.65 & .72 & & & & & & & & & & & $(0.85)$ & $0.31^{* *}$ & $0.29 *$ & $0.31^{* *}$ & $-0.36^{* *}$ \\
\hline 12. Anger - Trait & 17.97 & 4.58 & & & & & & & & & & & & $(0.81)$ & $0.52^{* *}$ & $0.58^{* *}$ & $-0.59 * *$ \\
\hline 13. Anger - Repression & 2.21 & .55 & & & & & & & & & & & & & $(0.78)$ & $0.49 * *$ & -0.16 \\
\hline 14. Anger - Inadequate Expr. & 7.30 & 2.01 & & & & & & & & & & & & & & $(0.68)$ & $-0.45^{* *}$ \\
\hline 15. Anger - Control & 2.28 & .55 & & & & & & & & & & & & & & & $(0.65)$ \\
\hline
\end{tabular}

Note. Scale reliabilities are shown in parentheses along the diagonal.

a Variable is dichotomous.

${ }^{*} p<.05$. ${ }^{* *} p<.01$. 
A general picture of the severity of psychological and physical violence present in our sample can be inferred from the descriptive statistics. The average frequency of psychological violence corresponded to about 45 occurrences per year (nearly once a week), and the average frequency of physical violence corresponded to approximately 11 times a year (almost once a month). These figures are higher than general population scores (Lafontaine and Lussier, in press; Straus, 1990) by ratios of six to one for psychological violence and three to one for physical violence.

While most of the predictor variables showed a correlation with husband violence measurements, a number of them did not show a significant direct link with husband physical aggression, namely dyadic adjustment consensus, dyadic adjustment affective expression, dyadic adjustment cohesion, anxious attachment, childhood witnessing of interparental violence, childhood victimization, anger repression, and felt intensity of anger. In addition, a subset of those variables was not significantly correlated with husbands' psychological aggression: dyadic adjustment affective expression, anxious attachment, childhood witnessing of interparental violence, and childhood victimization. Surprisingly, anxious attachment did not appear to be correlated to the dyadic adjustment scales. Examining the distribution of anxious attachment scores revealed that they were mostly elevated: very few of them were at the lower extremity of the scale. This restriction of variance may explain the lack of correlation observed.

The results of the omnibus moderated multiple regressions appear in Tables 2 and 3 . As shown in Table 2, anger repression and felt intensity of anger were found to significantly moderate the effects of predictor variables on physical violence, $F(8,54)=2.56, p=.02$ and $F(8,54)=2.24, p=.04$. Moderation effects were not found for anger trait, inadequate expression, and anger control. As for psychological violence, Table 3 shows that anger characteristics do not appear to moderate its link with predictor variables. Other contrasting results are revealed in Tables 2 and 3; in Table 2 , the model that excludes interaction effects accounts for very little of the variance in physical aggression scores, whereas the opposite is true of the psychological aggression scores (Table 3). 
Table 2: Summary of results for omnibus moderated multiple regression analyses of the interactions between predictor variables and anger subscale scores on physical aggression

\begin{tabular}{llllllllllll}
\hline Moderator & \multicolumn{2}{c}{ Repression } & \multicolumn{2}{c}{ Trait } & \multicolumn{3}{c}{ Inadequate } & \multicolumn{2}{c}{ Felt Intensity } & \multicolumn{2}{c}{ Control } \\
& & \multicolumn{9}{c}{ Expression } \\
Step & $\Delta F$ & $\Delta R^{2}$ & $\Delta F$ & $\Delta R^{2}$ & $\Delta F$ & $\Delta R^{2}$ & $\Delta F$ & $\Delta R^{2}$ & $\Delta F$ & $\Delta R^{2}$ \\
\hline 1 & 1.820 & .321 & 1.784 & .321 & 1.748 & .321 & 1.748 & .321 & 1.820 & .321 \\
2 & $2.562^{*}$ & $.223^{*}$ & 1.180 & .127 & 1.104 & .123 & $2.242^{*}$ & $.210^{*}$ & 1.360 & .140 \\
\hline
\end{tabular}

Step 1 included the following variables: anxious attachment, avoidant attachment, the four dyadic adjustment variables, childhood victimization, childhood witnessing of interparental violence, and the five anger scores.

Step 2 included interaction terms of the respective anger moderator with the following variables: anxious attachment, avoidant attachment, the four dyadic adjustment variables, childhood victimization, and childhood witnessing of interparental violence.

$* p<.05$.

Table 3: Summary of results for omnibus moderated multiple regression analyses of the interactions between predictor variables and anger subscale scores on psychological aggression

\begin{tabular}{llllllllllll}
\hline $\begin{array}{l}\text { Moderat } \\
\text { or }\end{array}$ & \multicolumn{2}{c}{ Repression } & \multicolumn{2}{c}{ Trait } & \multicolumn{2}{c}{$\begin{array}{c}\text { Inadequate } \\
\text { Expression }\end{array}$} \\
Step & $\Delta F$ & $\Delta R^{2}$ & $\Delta F$ & $\Delta R^{2}$ & $\Delta F$ & $\Delta R^{2}$ & $\Delta F$ & $\Delta R^{2}$ & $\Delta F$ & $\Delta R^{2}$ \\
\hline 1 & $6.634^{*}$ & $.633^{*}$ & $6.502^{*}$ & $.633^{*}$ & $6.369^{*}$ & $.633^{*}$ & $6.369^{*}$ & $.633^{*}$ & $6.634^{*}$ & $.633^{*}$ \\
2 & .865 & .052 & 1.430 & .080 & 1.063 & .064 & 1.896 & .101 & .440 & .028 \\
\hline
\end{tabular}

Step 1 included the following variables: anxious attachment, avoidant attachment, the four dyadic adjustment variables, childhood victimization, childhood witnessing of interparental violence, and the five anger scores.

Step 2 included interaction terms of the respective anger moderator with the following variables: anxious attachment, avoidant attachment, the four dyadic adjustment variables, childhood victimization, and childhood witnessing of interparental violence.

$* p<.05$.

Table 4 presents the multiple regression coefficients for psychological violence. Two variables were found to be significant positive correlates of psychological violence: anger trait $($ Beta $=.360, t(61)=2.47, p<.05)$ and inadequate expression of anger $($ Beta $=.449,+(61)=3.53, p<.01)$, while another one, the satisfaction subscale of dyadic adjustment, was inversely correlated (Beta $=-.355, t(61)=-2.04, p<.05)$. 
Table 4: Coefficients in the multiple regression involving psychological violence

\begin{tabular}{ccccc}
\hline Predictor & $\mathrm{B}$ & $\mathrm{SE}$ & $\beta$ & $\dagger$ \\
\hline (Constant) & .000 & .071 & & -.006 \\
Anger Trait & .073 & .029 & $.360^{*}$ & 2.474 \\
Anger Repression & .068 & .214 & .040 & .317 \\
Anger Control & -.055 & .218 & -.033 & -.252 \\
Anger Inadequate Expr. & .208 & .059 & $.449 * *$ & 3.532 \\
Anger - Felt Intensity & .005 & .137 & .004 & .037 \\
Dyadic Adj. Cohesion & .006 & .036 & .026 & .160 \\
Dyadic Adj. Satisfaction & -.066 & .033 & $-.355^{*}$ & -2.039 \\
Dyadic Adj. Affective Expr. & .021 & .042 & .054 & .489 \\
Dyadic Adj. Consensus & .008 & .032 & .028 & .256 \\
Avoidant Attachment & -.198 & .126 & -.242 & -1.569 \\
Anxious Attachment & -.123 & .086 & -.156 & -1.437 \\
Childhood Victim & -.197 & .192 & -.105 & -1.024 \\
Childhood Witness & .138 & .201 & .074 & .685 \\
\hline
\end{tabular}

Note: ${ }^{*} p<.05 .^{* *} p<.01$.

Follow-up regression analyses conducted to examine individual interaction terms, presented in Table 5, showed that anger repression interacts significantly with a number of variables to predict husband physical violence. The interaction term with dyadic adjustment cohesion accounted for $6 \%$ of the variance of physical violence; with dyadic adjustment satisfaction, 8.5\%; with affective expression and with avoidant attachment, 11\%; and with anxious attachment, 10\%. Felt intensity of anger was seen to interact with a different set of variables. Its interaction term with dyadic adjustment consensus accounted for $10 \%$ of the variance of husband physical violence, and its interaction term with childhood victimization accounted for $7 \%$. Other interaction terms were not significant at the .05 level. 
Table 5: Summary of moderated multiple regression analysis results for individual interactions of predictors with anger repression and felt intensity of anger (dependent variable: physical aggression)

\begin{tabular}{lllllllll}
\hline & \multicolumn{3}{l}{ Anger Repression } & \multicolumn{4}{c}{ Felt Intensity of Anger } \\
\hline Predictor & $\mathrm{B}$ & $\mathrm{SE}$ & $\beta$ & $\Delta R^{2}$ & $\mathrm{~B}$ & $\mathrm{SEB}$ & $\beta$ & $\Delta R^{2}$ \\
\hline Dyadic Adj. Cohesion & .051 & .023 & $.298^{*}$ & $.061^{*}$ & .013 & .020 & -.087 & .006 \\
Dyadic Adj. Satisfaction & .061 & .023 & $.360^{*}$ & $.085^{*}$ & .030 & .016 & .228 & .018 \\
Dyadic Adj. Affective Expr. & .134 & .044 & $.396^{* *}$ & $.107^{* *}$ & .024 & .031 & .105 & .008 \\
Dyadic Adj. Consensus & .049 & .030 & .213 & .034 & .056 & .019 & $.358^{* *}$ & $.101^{* *}$ \\
Avoidant Attachment & -.242 & .079 & $-.385^{* *}$ & $.110^{* *}$ & -.093 & .065 & -.181 & .028 \\
Anxious Attachment & -.220 & .077 & $-.354^{* *}$ & $.097^{* *}$ & -.097 & .075 & -.172 & .024 \\
Childhood Victim & -.242 & .188 & -.156 & .022 & -.333 & .144 & $-.291^{*}$ & $.067^{*}$ \\
Childhood Witness & .064 & .246 & .042 & .001 & -.063 & .155 & -.053 & .002 \\
\hline
\end{tabular}

Following Cohen, Cohen, Aiken and West (2003), we obtained simple slopes at high (one standard deviation above the mean) and low (one standard deviation below the mean) values of moderating anger variables. Figures 1-7 illustrate the significant interaction effects by plotting the simple regression lines at these values.

Figures 1 through 5 represent, respectively, the interaction of anger repression with avoidant attachment, anxious attachment, and dyadic adjustment affective expression, satisfaction and cohesion. Figures 6 and 7 represent, respectively, the interaction of felt intensity of anger with dyadic adjustment consensus and childhood victimization.

Figure 1: Interaction between avoidant attachment and anger repression (Repr.) on husband physical violence.

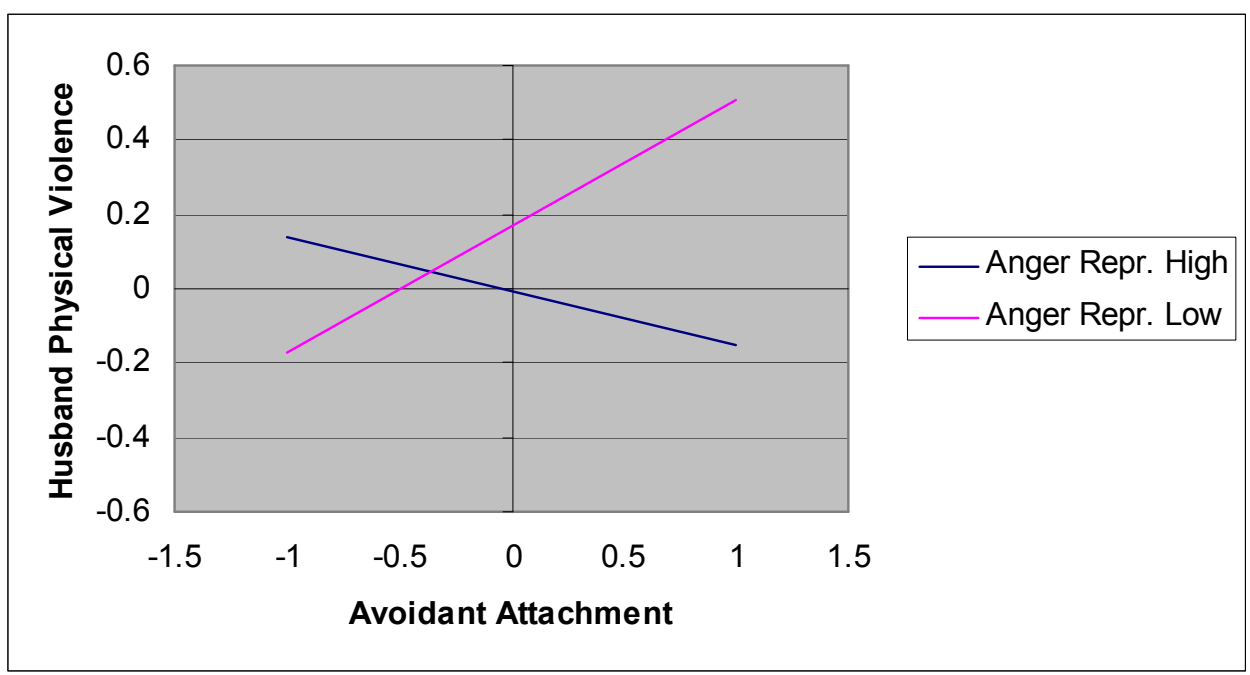


Figure 2: Interaction between anxious attachment and anger repression (Repr.) on husband physical violence.

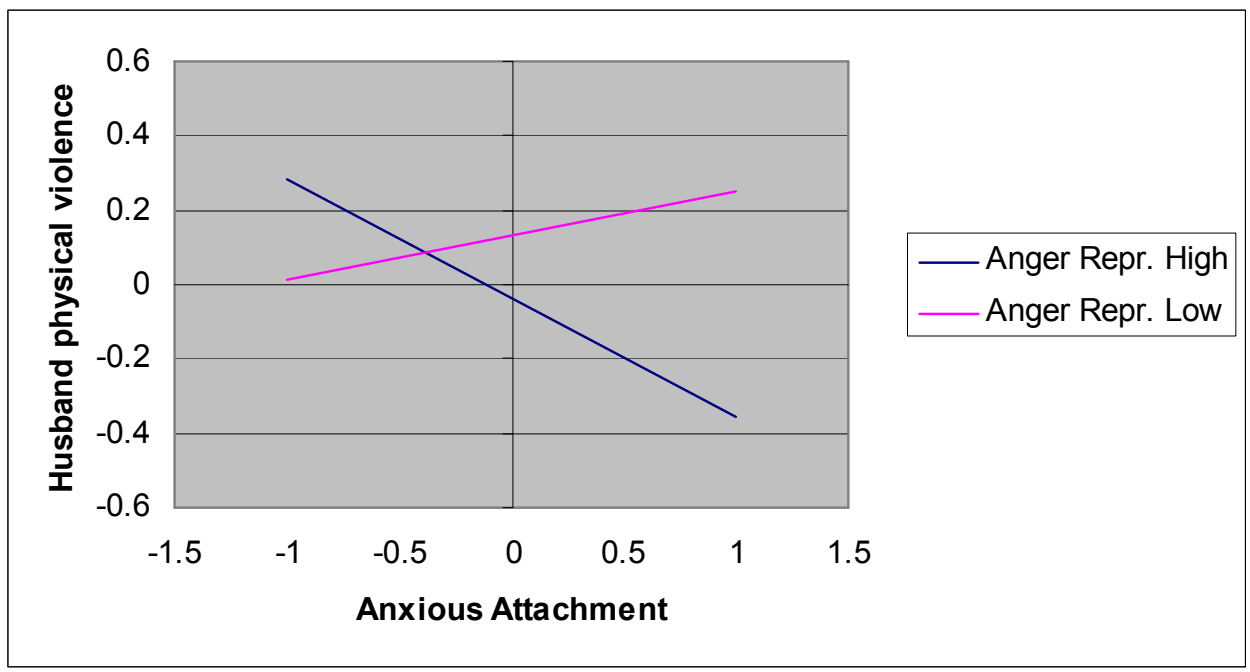

Figure 3: Interaction between dyadic adjustment affective expression and anger repression (Repr.) on husband physical violence

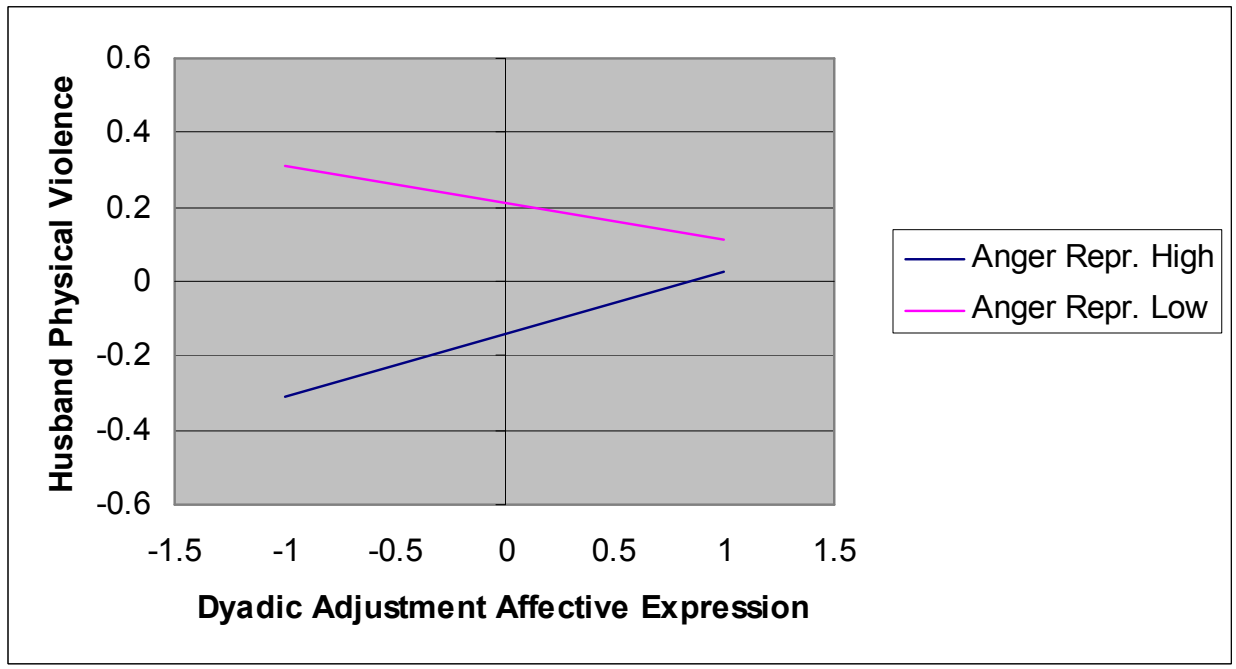


Figure 4: Interaction between dyadic adjustment satisfaction and anger repression (Repr.) on husband physical violence

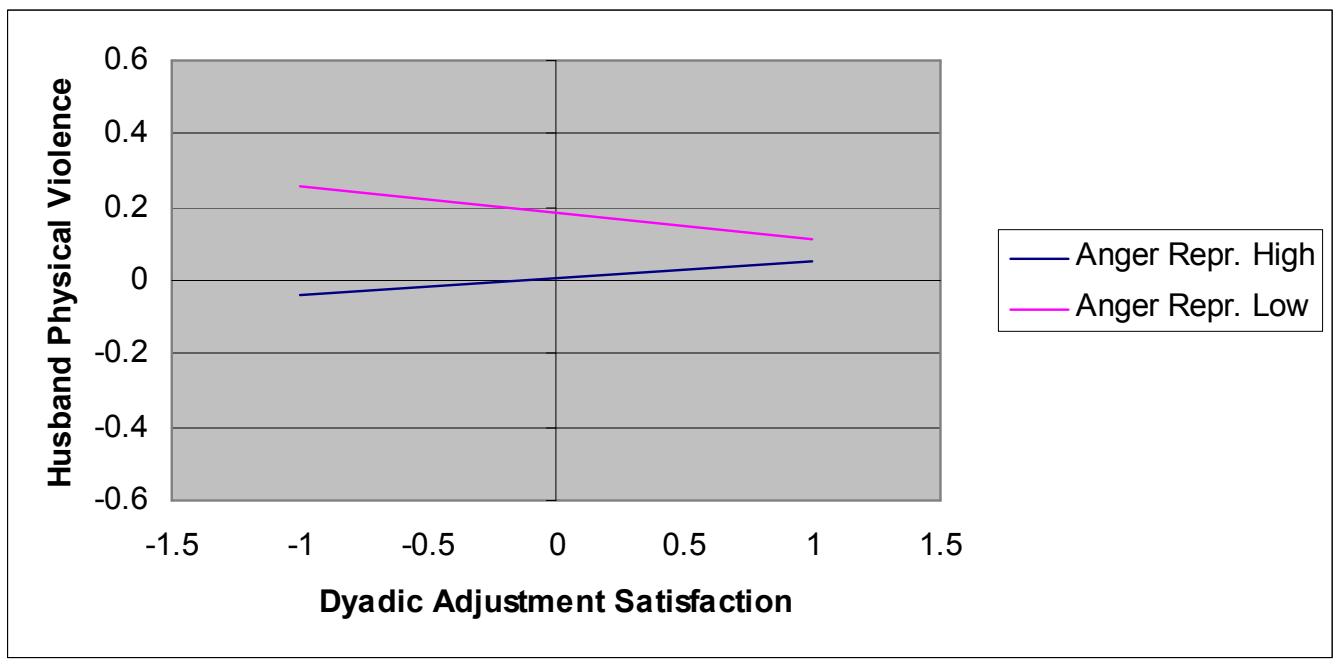

Figure 5: Interaction between dyadic adjustment cohesion and anger repression (Repr.) on husband physical violence

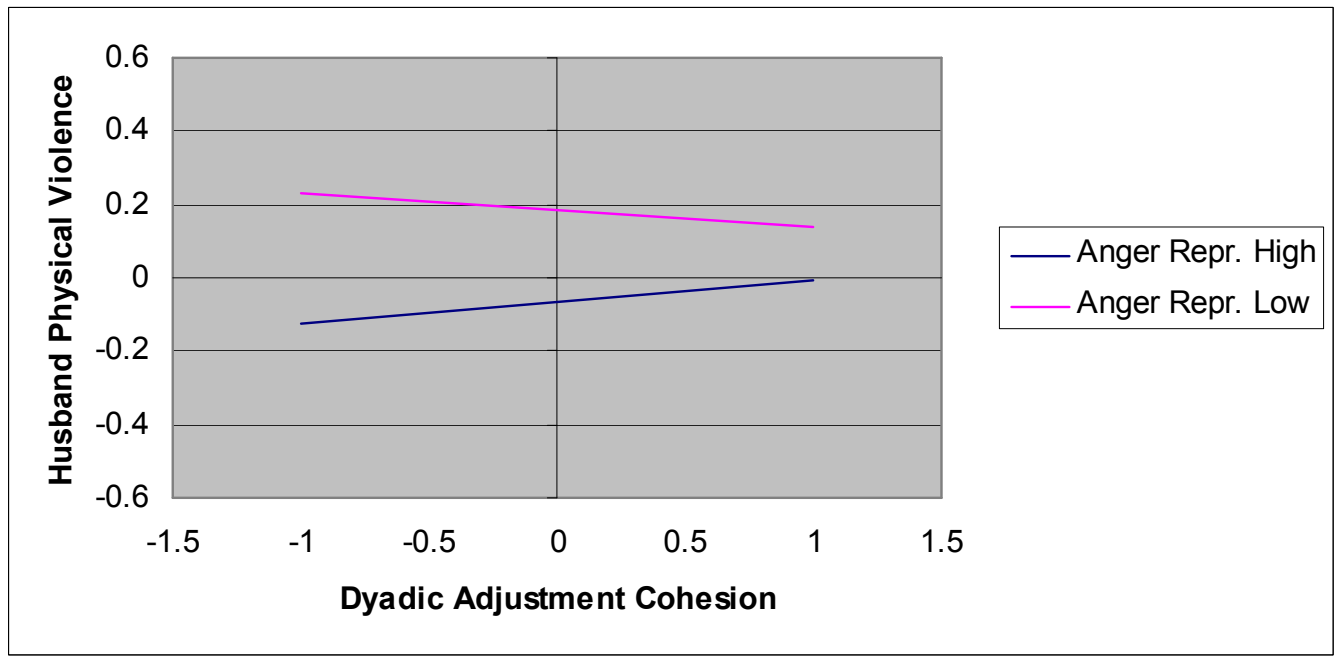


Figure 6: Interaction between dyadic adjustment consensus and felt intensity (Int.) of anger on husband physical violence

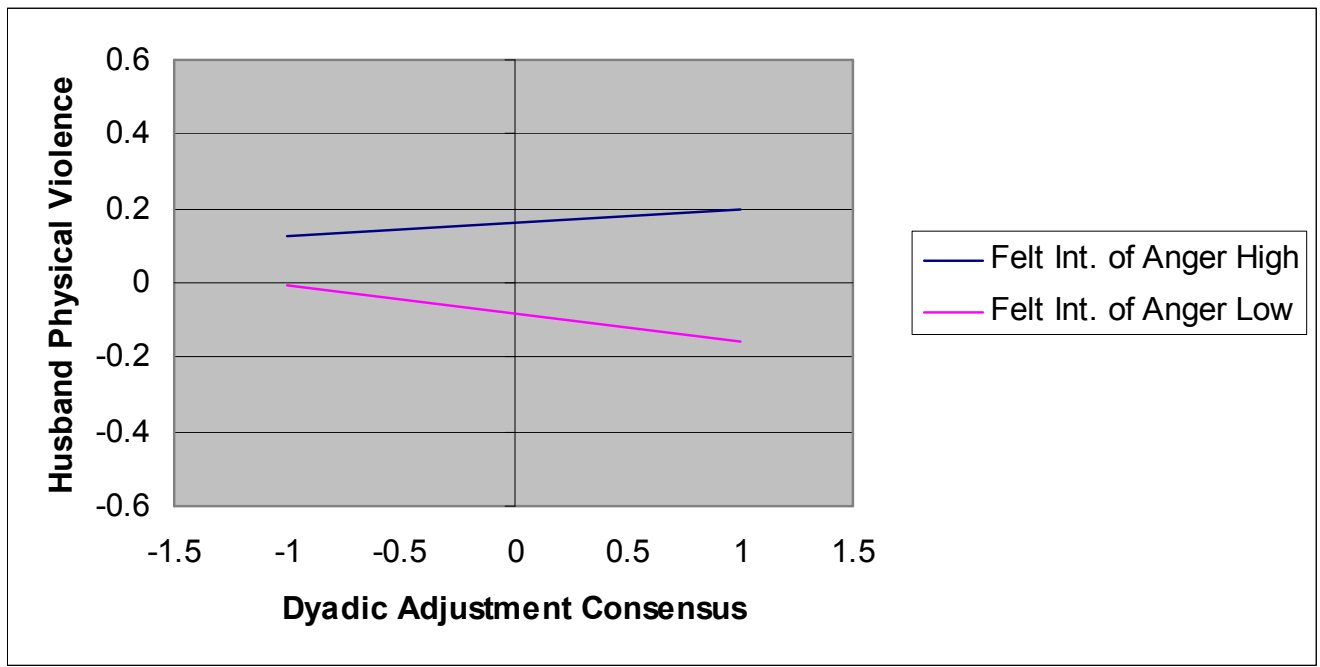

Figure 7: Interaction between childhood victimization and felt intensity (Int.) of anger on husband physical violence

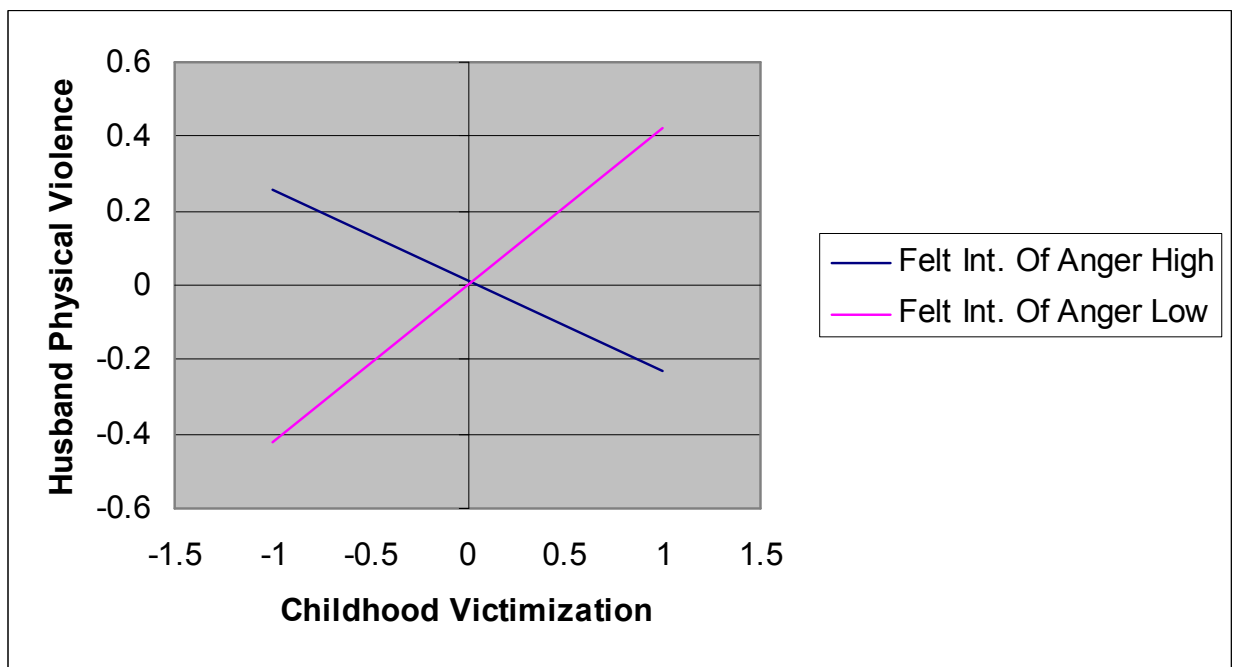

As shown in Figure 1, when men reported low repression of anger, the link between avoidant attachment and physical violence was significant and positive $(B=.34, t(61)=$ 3.2, $p=.002)$ but it was not significant when they reported high repression $(B=-.14, t(61)$ $=-1.3, p=.19)$. Figure 2 shows that when men reported low repression of anger, the link between anxious attachment and physical violence was not significant $(B=.12, t(61)=$ 1.3, $p=.20$ ) but it was significant and negative when they reported high repression $(B=-$ 
$.32, t(61)=-3.5, p<.0001)$. As displayed in Figure 3, when men reported low repression of anger, the link between dyadic adjustment affective expression and physical violence was not significant $(B=-.1, t(61)=-2.0, p=.053)$ but it was significant and positive when they reported high repression $(B=.17, t(61)=3.3, p=.001)$. As shown in Figure 4 , when men reported low repression of anger, the link between dyadic adjustment satisfaction and physical violence was significant and negative $(B=-.07, t(61)=-2.4, p=.02)$ but it was not significant when they reported high repression $(B=.05, t(61)=1.6, p=.11)$. Figure 5 shows that when men reported low repression of anger, the link between dyadic adjustment cohesion and physical violence was not significant $(B=-.04, t(61)=-1.6$, $p=.12)$ but it was significant and positive when they reported high repression $(B=.06$, $t(61)=2.1, p=.05)$. As displayed in Figure 6 , when men reported low felt intensity of anger, the link between dyadic adjustment consensus and physical violence was significant and negative $(B=-.076, t(61)=-2.8, p=.007)$ but it was not significant when they reported high repression $(B=.037, f(61)=1.4, p=.18)$. Finally, Figure 7 shows that when men reported low felt intensity of anger, the link between childhood victimization and physical violence was significant and positive $(B=.42, t(61)=2.3, p=.025)$ but it was not significant when they reported high repression $(B=-.025, t(61)=-1.4, p=.19)$.

\section{Discussion}

In the present study, we investigated whether anger in the couple relationship would moderate the effects of various predictors on the husbands' psychological and physical violence. We examined three different types of predictors of husband violence (personality variables: avoidant attachment and anxious attachment; couple variables: dyadic adjustment (satisfaction, cohesion, consensus, affective expression); personal history variables: childhood witnessing of interparental violence and childhood victimization), five components of couple-related anger (repression, felt intensity, control, trait, inadequate expression), and two forms of husband violence (psychological violence and physical violence).

The results of our study provide some support for our hypotheses that anger in the couple relationship would moderate the effects of all three types of predictors on husband violence. However, the predictors in our study were found to have contrasting relationships with the two forms of violence under investigation. Moderation effects were observed with physical violence but not with psychological violence. This runs contrary to our hypothesis that psychological aggression is more likely to be moderated by anger characteristics. Recalling our earlier observation that the direct effects largely explained variance in psychological aggression, this result may indicate that the overlap between anger and psychological violence in violent husbands is such that it leaves little room for a moderation relationship. More 
specifically, the direct correlation found between the dimensions of trait anger and inadequate expression of anger suggests that these aspects of anger are intimately connected to psychological aggression among violent husbands. Moreover, the level of satisfaction within the relation appears to provide a partial explanation of psychological violence, which suggests that unsatisfied husbands may be more prone to engage in psychological violence. Other relationships may also be involved in explaining psychological abuse; for instance, Lafontaine and Lussier (in press) found that anger variables explained the association between husbands' insecure attachment and intimate psychological violence.

If we look at the couple-related anger characteristics that were potential moderators in our study, two of them (anger repression and felt intensity of anger) were found to moderate the relationship between our various predictors and physical aggression, while the other three (anger control, inadequate expression of anger, and anger traits) would not be moderators in this relationship. Considering that anger repression and felt intensity of anger are the more internally-related anger characteristics experienced in the couple relationship leads to the suggestion that the more covert characteristics of anger are more likely to play a moderating role than the overt characteristics, and reinforce the idea that it would be advantageous to consider anger as a multidimensional construct in studies of violence.

Looking at the significant interaction effects for physical violence, the strongest and most consistent buffering effects were found for anger repression; it interacted with all the dyadic adjustment variables, except consensus, and both attachment variables to predict physical violence. For felt intensity of anger in the couple, significant interactions occurred with the consensus and childhood victimization variables. Overall, significant interactions accounted for $6 \%$ to $11 \%$ of the variance in physical aggression. These are substantial moderation effects (Champoux and Peters, 1987; Cohen, Cohen, West \& Aiken, 2003).

How can the direction of these interactions be interpreted? Anger repression was found to moderate the relationship between avoidant attachment and violence. It appears that violent outbursts are most likely when anger is not repressed and avoidant attachment is elevated. When anger is repressed, however, there does not seem to be a relationship between avoidant attachment and violence. Because of the connection between avoidant attachment and antisocial personality (Holtzworth-Munroe and Stuart, 1994; Egeland, Weinfield, Bosquet and Cheng, 2000), this result is consistent with the notion that there exists a "Type I" of batterers who exhibit antisocial personalities and are not driven to repress anger (Gottman et al, 1995). 
Anger repression also moderated the relationship between anxious attachment and violence; when anger is repressed, the presence of anxious attachment reduces husband violence, whereas low anxious attachment is associated with higher physical violence. This may suggest that anxiously attached husbands fear losing their partner enough that they do not let their repressed anger surface in the form of violence, and that conversely, husbands low in anxious attachment are relatively indifferent of their partner. This result is analogous to that of Lafontaine and Lussier (in press), who found that high trait anger and low anger control were linked to a relationship between low anxious attachment and increased physical violence in a non-clinical sample. However, the anger variables that stood out in Lafontaine and Lussier's study were different than the ones we found. This suggests a qualitative difference between the ways in which violence erupts in violent husbands who require treatment and the general population.

In addition, anger repression was found to moderate the relationships between dyadic adjustment (affective expression, satisfaction, and cohesion) and violence, much in the same manner for each one (compare Figures 3, 4, and 5). Men who tend not to repress anger show less violence as dyadic adjustment increases, while the opposite trend is observed for men who tend to repress anger. Moreover, the simple slopes appear to converge towards the mean in the region of high dyadic adjustment. Thus, for husbands who are comparatively well-adjusted in their couple, anger repression appears to have little bearing on the level of violence; however, when a husband is dyadically maladjusted, low anger repression signals increased risk for violence. This perspective suggests that anger repression may act as a coping mechanism for men who are not well-adjusted in their couple, driving them to react to marital problems in ways other than outward violence.

The felt intensity of anger was identified as a moderator of the relationship between dyadic adjustment consensus and husband physical violence. It appears that, for men who report a low intensity of anger, violence decreases significantly as consensus increases while it remains elevated for men who experience intense anger. By itself, the felt intensity of anger was not correlated to physical aggression (Table 1); this moderation clarifies the role that anger intensity plays with respect to men's violence against their partner.

Finally, felt intensity of anger in the couple was found to moderate the relationship between childhood victimization and physical violence in husbands. Violence was least frequent among men who felt a low intensity of anger and were not battered as children. For male partners who feel anger more intensely, childhood victimization appears to be unrelated to the degree of violence exhibited. Accordingly the fact 
that victimization as a child would not impact on the link between anger and marital violence would suggest that social learning theory (Bandura, 1977) does not always offer a complete explanation for the causes of husband violence. Social learning theory would imply that victimized children would learn from observation and modeling after their violent parent's behavior. Accordingly, one must expect that observation of violent behavior would predispose to imitate these aggressive behaviors and develop a pattern of violent behaviors when frustrated or angry. Our results would imply that this trans generationnal pattern of violence would not always be there and that other issues are at stake to explain violence, like poor problem solving skills, dysfunctional patterns of communication, etc.

Our hypothesis that anger in the couple relationship would have the greatest interaction with dyadic adjustment variables was partially corroborated by our results, as was the moderation effect of felt intensity of anger. Our hypothesis was not confirmed for anger repression, the latter interacting more extensively and consistently with attachment variables. The results we obtained might be better explained by noting that the variables that interact with anger repression are of an emotional nature, while those that interact with felt intensity of anger are not. This may reflect the fact that anger repression in the couple relationship generally controls whether other emotions in the couple will influence behavior. By contrast, the interactions we identified for felt intensity of anger suggest that this characteristic interplays with less emotional experiences in the here and now. Together, these observations again underscore the complexity of anger as experienced in the couple.

Our findings may assist in the design of interventions with violent husbands, because they indicate where the moderator role of anger may be brought into play to reduce the level of violent behavior towards the partner, for example, through anger control training. In cases where the goal is to reduce psychological violence, the constructiveness of altering a male partner's anger characteristics does not appear to depend on other variables. Where reduction of physical violence is the goal, however, it would be constructive to consider anger in light of its interactions with other factors. Based on the results of our study, the internally experienced aspects of anger (repression and felt intensity) seem to be of greater relevance. In particular, the moderation relationships that we have uncovered provide a number of specific indications for therapy. First, if violent husbands who exhibit high avoidant or anxious attachment were to repress anger more, it could reduce the amount of physical violence. This suggests that anger management training may be especially effective for intensely-attached violent men. Second, an analogous observation holds for men who are not well-adjusted to their couple: anger management might especially be 
beneficial for reducing acts of violence by those men. Third, our results suggest that it would be desirable for violent men who don't feel intense anger to learn to attain an increased consensus in their marital relationship in order to reduce the occurrence of violence, while violent husbands who already have a good degree of consensus should seek ways of reducing the intensity of anger that they experience. Finally, for violent men who were not battered as children, working towards a state where anger is felt in a less intense manner could be effective in reducing violence towards the female partner.

While the findings of this study are valuable, a number of limitations should be acknowledged. First, because our data is generated from self-reports, there may be bias in the values collected. People tend to underreport their own violence; however, only a weak negative relationship has been observed between social desirability and self-reports of intimate violence in the general population (Sugarman and Hotaling, 1997). In addition, since our sample was composed of men who had already acknowledged their violent behavior toward their partner, this bias is probably considerably reduced. A second potential limitation of our study stems from the relatively small sample size and the limited statistical power inherent to hierarchical multiple regression analyses (Champoux and Peters, 1987). Null findings should be interpreted carefully, because there are non-negligible chances that other moderation effects were present and went undetected.

Thirdly, because our sample consisted of men who are under treatment for partner violence, it is not possible to ascertain whether the results generalize to male partners from the general population. Similarly, our sample did not include men who committed more extreme acts of violence towards their partner, such as incarcerated batterers. It may however be that no single model applies across the whole spectrum of the husband violence phenomenon. Of course, the present data is cross-sectional in nature, and a longitudinal design would help shine light on the temporal aspect of the relationships under investigation.

As noted in the results section, a number of variables found to be correlated with husband violence in previous work did not show a direct link in our analyses, especially in the case of physical violence (for instance, childhood witnessing of violence). Though this may be due to the limited size of our sample, it may also be attributed to the fact that our sample did not include non-violent men. Correlations may be absent for variables that differentiate between violent and non-violent men, but are not indicative of the degree of violence in men who abuse their partner. It should be noted that most of the variables in question showed significant 
moderation relationships with aggression, which suggests that to understand the role of those variables it may be beneficial to consider interaction effects.

Further work is necessary to pursue the exploration of the results obtained in this study. While our findings were restricted to anger characteristics as moderators, it is possible that other variables play a moderation role. Furthermore, our study did not include all predictors of husband violence; it would be interesting to examine more closely the similarities and differences between the interactions of predictors belonging to the different clusters that we used (personal history, psychological, personality, and dyadic variables) and anger characteristics. Additionally, conducting studies similar to ours but with larger samples might help identify new moderation relationships that our research did not reveal.

An effort should be made in future work to include data from sources other than the actual perpetrators of violence. The inclusion of observational measures or thirdparty reports in addition to self-reports may help provide a more reliable picture of husband violence (Holtzworth-Munroe, 1997). Finally, a potentially important research avenue that could build on the present study would be to test intervention strategies that include anger management for violent men. For example, intervention approaches could be adapted according to the type of violence perpetrated, the men's anger profile (i.e. propensity towards repression and experiencing feeling of anger towards partner), and the presence or absence of the characteristics highlighted in our results.

\section{References}

Albus, K.E., Weist, M.D., \& Perez-Smith, A.M. (2004). Associations between youth risk behavior and exposure to violence: Implications for the provision of mental health services in urban schools. Behavior Modification. 28, 548-564.

Babcock, J., Waltz, J., Jacobson, N.S. \& Gottman, J. (1993). Power and violence: The relation between communication patterns, power discrepancies, and domestic violence. Journal of Consulting and Clinical Psychology, 61, 40-50.

Bandura, A. (1977). Social Learning Theory. New York: General Learning Press.

Barnett, O., Fagan, R. \& Booker, J. (1991). Hostility and stress as mediators of aggression in violent men. Journal of Family Violence, 6, 217-241. 
Barling, J. (1996). The prediction, experience, and consequences of workplace violence. In G.R. VandenBos and E.Q. Bulatao (Eds), Violence on the Job: Identifying Risks and Developing Solutions (29-49). Washington, DC: American Psychological Association.

Berns, S.B., Jacobson, N.S., \& Gottman, J.M. (1999). Demand-withdraw interaction in couples with a violent husband. Journal of Consulting \& Clinical Psychology. 67, 666-674.

Berkowitz, L. (1989). Frustration-aggression hypothesis: Examination and reformulation. Psychological Bulletin, 106, 59-73.

Black, D.A., Schumacher, J.A., Smith Slep, A.M., \& Heyman, R.E. (1999). Risk Factors for Partner Abuse and Child Maltreatment: A Review of Literature. C.M. Allen, Editor. Retrieved July, 15, 2004 from CYFERNet Web site, http://www.cyfernet.org

Brennan, K.A., Clark, C.L. \& Shaver, P.R. (1998). Self-Report Measurement of Adult Romantic Attachment: An Integrative Overview. In J.A. Simpson and W.S. Rholes (Eds.), Attachment Theory and Close Relationships, 46-78. New York: Guilford Press.

Burman, B., Margolin, G. \& John, R.S. (1993). America's angriest home videos: Behavioral contingencies observed in home reenactments of marital conflict. Journal of Counseling and Clinical Psychology, 61, 28-39.

Champoux, J. E. \& Peters, W. S. (1987). Form, effect size and power in moderated regression analysis. Journal of Occupational Psychology, 60, 243-255.

Cohen. J., Cohen, P., West, S.G., \& Aiken, L.S. (2003). Applied multiple regression / correlation analysis for the behavioral sciences (2nd ed.). Mahwah, NJ: Lawrence Erlbaum.

Colder, C.R. \& Stice, E. (1998). A longitudinal study of the interactive effects of impulsivity and anger on adolescent problem behavior. Journal of Youth \& Adolescence, 27, 255274.

Date, A.L., \& Ronan, G.F. (2000). An Examination of Attitudes and Behaviors Presumed to Mediate Partner Abuse: A Rural Incarcerated Sample. Journal of Interpersonal Violence, $11,1140-1155$.

Dibble, U. \& Straus, M.A. (1980). Some social structure determinants of inconsistency between attitudes and behavior: The case of family violence. Journal of Marriage and the Family, 1, 71-80. 
Dutton, D. \& Starzomski, A. (1994). Psychological differences between court-referred and self-referred wife assaulters. Criminal Justice and Behavior 21 , 203-222.

Dye, M.L. \& Eckhardt, C.I. (2001) Irrational Beliefs and Dysfunctional Attitudes in Violent Dating Relationships. Violence \& Victims, 3, 337-350.

Egeland, B., Weinfield, N. S., Bosquet, M., \& Cheng, V. K. (2000) . Remembering, repeating and working through: Lessons from attachment-based interventions. In J. D. Osofsky \& H. E.

Fitzgerald (Eds.), Infant Mental Health in Groups at High Risk (Vol. 4). WAIMH Handbook of Infant Mental Health (Fol. 4). New York: John Wiley \& Sons, Inc.

Felitti, V., Anda, R., Nordenberg, D., Williamson, D., Spitz, A., Edwards, V., et al. (1998). Relationship of childhood abuse and household dysfunction to many of the leading causes of death in adults. American Journal of Preventive Medicine, 14, 245-258.

Feldman, C.M. \& Ridley, C.A. (2000). The role of conflict-based communication responses and outcomes in male domestic violence toward female partners. Journal of Social \& Personal Relationships, 17, 552-573.

Gosselin, M., Lafontaine, M.F. \& Bélanger, C. (2006) L'impact de l'attachement sur la violence conjugale : l'état de la question. Bulletin de Psychologie, 58 (5), N479, 2005, p. 579-588.,

Heyman, R.E., O'Leary, K.D. \& Jouriles, E.N. (1995). Alcohol and aggressive personality styles: Potentiators of serious physical aggression against wives? Journal of Family Psychology, 9, 44-57.

Holtzworth-Munroe, A., \& Stuart, G. (1994). Typologies of male batterers: Three subtypes and the differences among them. Psychological Bulletin, 116, 476-497.

Holtzworth-Munroe, A., Bates, L., Smutzler, N., \& Sandin, E. (1997). A brief review of the research on husband violence. Aggression and Violent Behavior, 1, 65-99.

Hotaling, G. \& Sugarman, D. (1986). An analysis of risk markers in husband to wife violence: The current state of knowledge. Violence and Victims, 1, 101-124.

Howell, M. \& Pugliesi, K. (1988). Husbands who harm: Predicting spousal violence by men. Journal of Family Violence, 3, 15-27. 
Jacobson, N.S., Gottman, J.M., Waltz, J., Rushe, R., Babcock, J. \& Holtzworth-Munroe, A. (1994). Affect, verbal content, and psychophysiology and the argument of couples with a violent husband. Journal of Consulting and Clinical Psychology, 62, 982-988.

Julian, T. \& McHenry, P. (1993). Mediators of male violence toward female intimates. Journal of Family Violence, 8, 39-55.

Lafontaine, M.F. \& Lussier, Y. (in press). Does Anger Against the Partner Mediate and Moderate the Link Between Romantic Attachment and Intimate Violence? Journal of Family Violence.

Lafontaine, M.F. \& Lussier, Y. (2001). Structure bidimensionnelle de l'attachement amoureux: anxiété face à l'abandon et évitement de l'intimité. Revue canadienne des sciences du comportement, 35, 56-60.

Laughrea, K., Bélanger, C. \& Wright, J. (1996). L'inventaire de l'expérience de la colère en situation sociale et conjugale: validation auprès de la population adulte québécoise. Science et comportement, 1, 71-94.

Laughrea, K., Bélanger, C., Wright, J., \& McDuff, P. (1997). L'étude de la colère au sein des relations conjugales. International Journal of Psychology, 32, 155-167.

Laughrea, K. Wright, J., McDuff, P. \& Bélanger, C. (2000). A typology of anger profiles in couples. Journal of Couples Therapy, 9, 85-107.

Leonard, K. \& Blane, H., 1992. Alcohol and marital aggression in a national sample of young men. Journal of Interpersonal Violence, 7, 19-30.

Lussier, Y., Valois, P., Sabourin, S. \& Dupont, G. (1998). Dyadic adjustment scale: An item response theory analysis. American Psychological Association 106 th Convention. San Francisco.

Maiuro, R.D., Cahn, T.S., Vitaliano, P.P, Wagner, B.C. et al. (1988). Anger, hostility, and depression in domestically violent versus generally assaultive men and nonviolent control subjects. Journal of Consulting \& Clinical Psychology, 56, 17-23.

Margolin, G., John, R.S., \& Gleberman, L. (1988). Affective responses to conflictual discussions in violent and nonviolent couples. Journal of Consulting and Clinical Psychology. 1, 24-33. 
Margolin, G., John, R.S., \& Foo, L. (1998). Interactive and unique risk factors for husbands' emotional and physical abuse of their wives. Journal of Family Violence, 13, 315-344.

Mauricio, A.M. \& Gormley, B. (2001). Male perpetration of physical violence against female partners. Journal of Interpersonal Violence, 16, 1066-1081.

McGregor, M., Tutty, L.M., Babins-Wagner, R., \& Gill, M. (2002). The long term impacts of group treatment for partner abuse. Canadian Journal of Community Mental Health, 21 , 67-84.

McKenry, P.C., Julian, T.W. \& Gavazzi, S.M. (1995). Toward a biophysical model of domestic violence. Journal of Marriage and the Family, 57, 307-320.

Murphy, C.M., \& O'Leary, K.D. (1989). Psychological aggression predicts physical aggression in early marriage. Journal of Consulting and Clinical Psychology, 57, 579-582.

National Research Council (1996). Understanding Violence Against Women. Washington: National Academy Press.

O'Leary, K.D., Malone, J. \& Tyree, A. (1994). Physical aggression in early marriage: Prerelationship and relationship effects. Journal of Consulting and Clinical Psychology, $62,594-602$.

Pan, H., Neidig, P. \& O'Leary, D. (1994). Predicting mild and severe husband-to-wife physical aggression. Journal of Consulting and Clinical Psychology, 62, 975-981.

Pedhazur, E.J. (1973). Multiple regression in behavioral research: Explanation and prediction. Chicago: Rinehart \& Winston.

Porcerelli, J.H., Cogan, R., \& Hibbard, S. (2004). Personality characteristics of partner violent men: A Q-sort approach. Journal of Personality Disorder, 18, 151-162.

Ramos, B.M, Carlson, \& B.E., McNutt, L.-A (2004). Lifetime abuse, mental health, and African American women. Journal of Family Violence, 19, 153-164

Rennison, C. \& Planty, M. (2003). Nonlethal intimate partner violence: Examining race, gender, and income patterns. Violence \& Victims, 18, 433-443.

Rosenbaum, A. \& O'Leary, K.D. (1981). Children: The unintended victims of marital violence. American Journal of Orthopsychiatry, 51, 692-699. 
Schat, A. \& Kelloway, E.K. (2003). Reducing the adverse consequences of workplace aggression and violence: The buffering effects of organizational support. Journal of Occupational Health Psychology, 8, 110-122.

Sharpe, D. \& Taylor, J.K (1999). An examination of variables from a social-developmental model to explain physical and psychological dating violence. Canadian Journal of Behavioural Science, 31, 165-175.

Siegel, J.M. (1986). The multidimensional anger inventory. Journal of Personality and Social Psychology, 51, 191-200.

Statistics Canada (2001). Family Violence in Canada: A Statistical Profile

Statistics Canada (2002) Family Violence in Canada: A Statistical Profile, Canadian Center for judicial statistics, Ottawa.

Spanier, G.B. (1976). Measuring dyadic adjustment: New scales for assessing the quality of marriage and similar dyads. Journal of Marriage and the Family, 38, 15-28.

Spielberger, C.D. (1988). State-trait Anger Expression Inventory (STAXI). Odessa, FL: Psychological Assessment Resources.

Spielberger, CD., Krasner, S. and Solomon, E. (1988). The experience, expression, and control of anger. In C.D. Spielberger and J.N. Butcher (Eds.), Health psychology: Individual differences and stress (vol. 3, 89-108).

Stith, S.M. \& Farley, S.C. (1993). A predictive model of male spousal violence. Journal of Family Violence, 8, 183-201.

Stith, S. \& Hamby, S.L. (2002). The anger management scale: Development and preliminary psychometric properties. Violence and Victims, 4, 383-402.

Straus, M.A., Gelles, R.J. \& Steinmetz, S.K. (1980). Behind closed doors: Violence in the American family. Garden City: Doubleday Press.

Straus, M.A. \& Gelles, R.J. (1986). Societal change and change in family violence from 1975 to 1985 as revealed by two national surveys. Journal of Marriage and the Family, 48, 465-479. 
Straus, M.A., Hamby, S.L., Boney-McCoy, S. \& Sugarman, D.B. (1996). The Revised Conflict Tactic Scales (CTS-2): Development and preliminary psychometric data. Journal of Family Issues, 3, 283-316.

Sugarman, D.B. \& Hotaling, G.T. (1989). Violent men in intimate relationships: An analysis of risk markers. Journal of Applied Social Psychology, 19, 1034-1048.

Sugarman, D. B., \& Hotaling, G. T. (1997). Intimate violence and social desirability: A metaanalytic review. Journal of Interpersonal Violence, 12, 275-290.

Tetrick, L.E. \& LaRocco, J.M. (1987). Understanding, prediction, and control as moderators of the relationships between perceived stress, satisfaction, and psychological well-being. Journal of Applied Psychology, 72, 538-543.

Tjaden, P. \& Thoennes, N. (2000). Full report of the prevalence, incidence, and consequences of intimate partner violence against women: Findings from the national violence against women survey. Washington: National Institute of Justice.

\section{About the authors}

Dr. Claude Bélanger is a full professor and director of the laboratory for the study of couples at the University of Quebec in Montreal, as well as associate professor in the Psychiatry Department at McGill University and researcher at the Douglas University Mental Health University Institute. His primary research interests include predictors of marital adjustment, problem solving behaviours in couples, and anxiety and marital functioning.

Correspondence should be addressed to Dr. Bélanger at belanger.claude@uqam.ca

Dr. Hélène Brisebois did her Ph.D. studies at the University of Quebec in Montreal under the direction of Professor Bélanger. Her interests include couples and marital violence. She now practices as a clinical psychologist. 